\title{
Complicated fronto-orbital mucopyocele presenting with proptosis: a case report
}

\author{
Mehmet Zafer Berkman'1, Ezgi Akar', Mehmet Ufuk Akmil2, Sevki Gok² \\ ${ }^{1}$ Department of Neurosurgery, Acibadem Maslak Hospital, Istanbul, Turkey \\ ${ }^{2}$ Department of Neurosurgery, Haydarpasa Numune Training and Research Hospital, Istanbul, Turkey
}

\begin{abstract}
Mucoceles are cystic lesions of the paranasal sinuses which develop as a result of accumulation of mucous secretion due to obstruction of the ostium of the sinuses. Despite their benign behavior, they may enlarge progressively and project into adjacent structures by destructing the bony walls of the sinuses. Frontal mucoceles may get infected and extend towards orbital cavity and compress the orbit by eroding the bony walls of the orbital cavity. Endoscopic and external approaches are performed in the surgical treatment. We report a case of complicated fronto-orbital mucopyocele which eroded the orbital roof and extended into the orbital cavity and discuss the surgical treatment strategy under the light of the current literature.
\end{abstract}

Key words: External approach; fronto-orbital mucocele; mucocele; mucopyocele.

$\mathrm{M}_{8}$ ucoceles are benign, progressive and locally aggressive lesions occurring by accumulation of secretion within the paranasal sinuses [1]. Paranasal sinus mucoceles are usually seen in frontal (65\%), anterior ethmoid (30\%) and maxillary sinuses (3-10\%). Posterior ethmoid and sphenoid sinuses are rarely involved [2,3]. Mucoceles extend into the surrounding tissues by eroding the sinus walls and cause pressure effect after reaching a certain size. The patients usually present with displacement of the eyeball in outer or lower direction, diplopia, eye pain, headache, Horner syndrome or panhypopituitarism. Frontal mucoceles can be complicated by infections and extend into the orbital cavity by destroying orbital walls $[1,4]$.
The treatment of mucoceles is surgical. Mucoceles are treated surgically either with external or endoscopic approaches. Endoscopic approach is recommended in uncomplicated mucoceles due to a low risk of recurrence [5]. However, it is suggested that external approaches will be more convenient in complicated infectious cases extending into the surrounding tissues due to bony destruction $[5,6]$.

\section{CASE REPORT}

A 63-year-old male patient presented with complaints of gradually increasing misalignment of the eye, ocular deformity, headache and pain in the left

Received: October 19, 2014 Accepted: December 09, 2014 Online: April 24, 2015

Correspondence: Dr. Ezgi AKAR. Haydarpasa Numune Egitim ve Arastirma Hastanesi, Beyin ve Sinir Cerrahisi Klinigi, Tibbiye Caddesi, 34668 Uskudar, Istanbul, Turkey. 

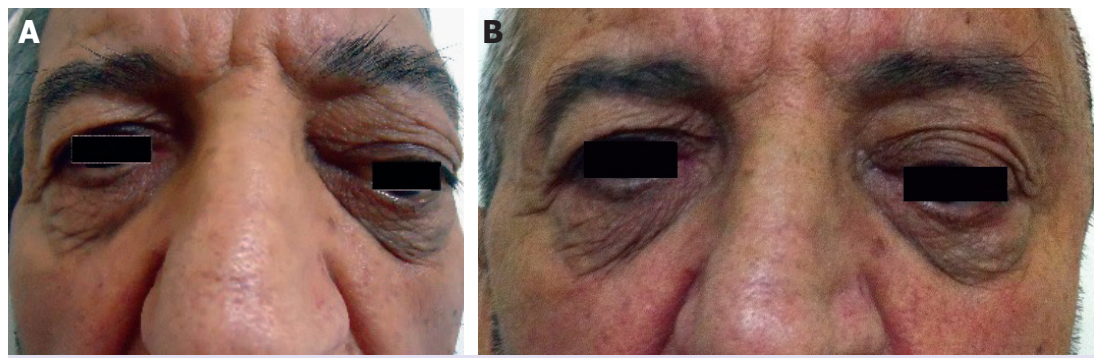

FIGURE 1. (A) Preoperative proptosis of the left eye. (B) Proptosis of the patient regressed within hours after surgery.

eye approximately for 5 years. At physical examination, an asymptomatic left eye was detected excepting proptosis (Figure 1). Neurological examination revealed restricted movements of the left eye in both downward and outward directions. Confrontation visual field assessment test of the patient was within normal limits without any visual impairment. Laboratory values were also within normal limits. A left fronto-orbital mucopyocele was seen during magnetic resonance 1maging (MRI) of the patient (Figure 2a). Computed tomography (CT) revealed a bony defect in the left orbital roof caused by mucopyocele on the left orbital roof (Figure $2 b$ ).

After preoperative assessment of the patient, surgery was planned. A modified left pterional craniotomy was performed. After removal of the skull bone flap, it was observed that infected mucocele extended into the extradural region by eroding posterior wall of the frontal sinus. Dark viscous abscess material was aspirated. The culture obtained from the material was negative. After removal of the mu-
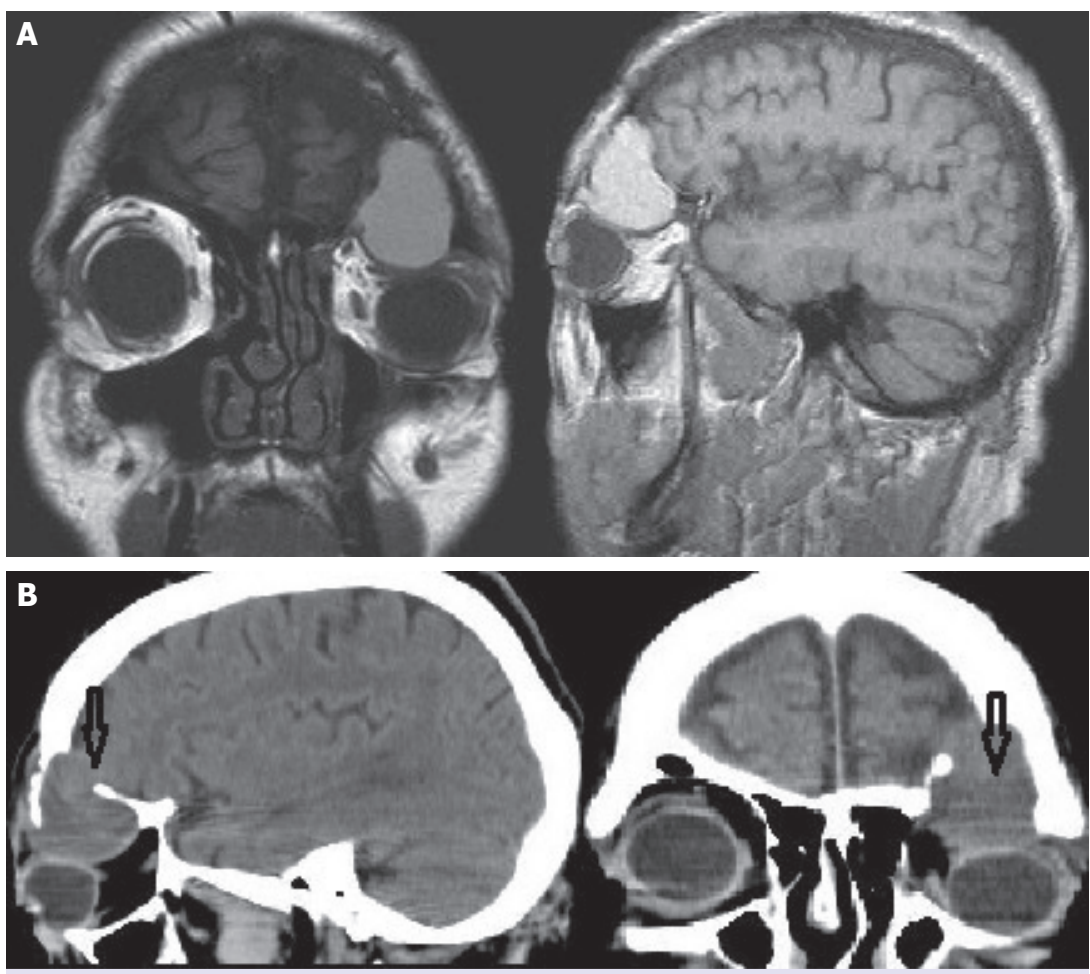

FIGURE 2. (A) A left fronto-orbital mucopyocele is seen on MRI of the patient. (B) CT image of a bony defect in the left orbital roof caused by mucopyocele localized on the left orbital roof. 


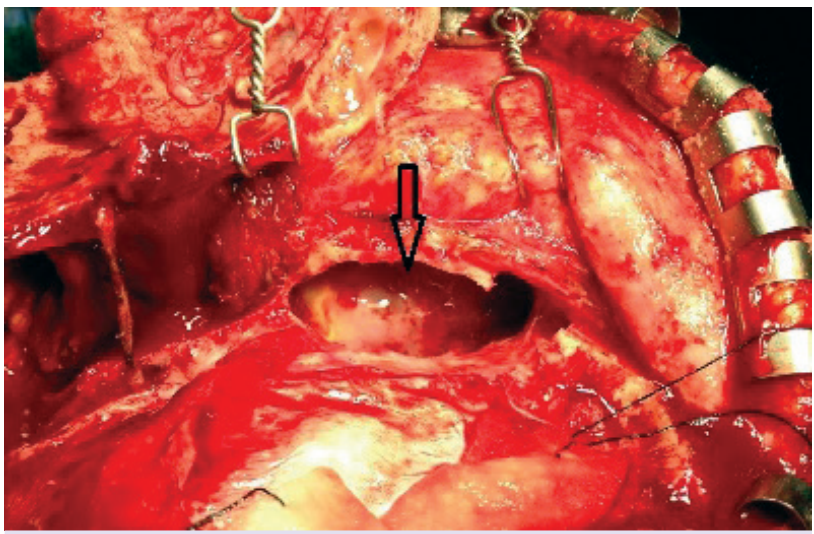

FIGURE 3. A bony defect in the orbital roof due to destruction caused by mucopyocele.

copyocele together with its capsule, a bony defect was observed in the orbital roof due to destruction caused by mucopyocele (Figure 3). Dura mater was observedly to be intact. Following cleaning of surgical site, frontal sinus was cranialized with pericranial flap and the sinus ostium was obliterated. Orbital defect was not repaired.

Postoperative follow-up of the patient was uneventful and proptosis of the patient regressed within hours after the surgery (Figure 1b). Postoperative MRI revealed that mucopyocele had been excised (Figure 4).

\section{DISCUSSION}

Mucoceles are slow-growing cystic lesions developing secondary to obstruction of the sinus ostium [5].
The etiological factors such as mucosal inflammation of the sinus, nasal polyp, anatomical variations of the nasal cavity, tumors or traumas cause mucocele formation by triggering chronic inflammation of the sinus mucosa $[4,5,6]$. Mucoceles occurring due to cystic dilation of the sinus mucosa and retention of secretion are located in the frontal, maxillary, ethmoid and rarely in the sphenoid sinuses with decreasing rates of prevalence [1].

As slow-growing lesions, mucoceles can remain asymptomatic for a long period of time $[4,7,8]$. Mucoceles usually manifest clinical symptoms by eroding the bones of the sinus walls and causing pressure effect on the adjacent anatomical structures after reaching a certain size [7]. Due to anatomical proximity, orbital symptoms are frequently encountered. Mucoceles account for 4-8.5\% of the expanding orbital masses [7]. Mucoceles with orbital involvement generally present with a non-infiltrating mass effect resulting in globe displacement, diplopia, proptosis, lid swelling, palpable mass, ptosis and reduced vision [5, 7]. Frontoethmoidal mucoceles often present with swelling in the superonasal and medial canthal regions, ptosis and inferolateral globe displacement. When a mucocele is infected, it is called a mucopyocele [5]. In this case presentation, infected mucocele originating from the frontal sinus extending into the orbital cavity by destroying frontal sinus and orbital roof with resultant symptoms of proptosis and eye pain was presented.

MRI is the gold standard diagnostic tool successful in demonstrating soft tissue lesions. CT is used due to its superiority in the visualization of bones,

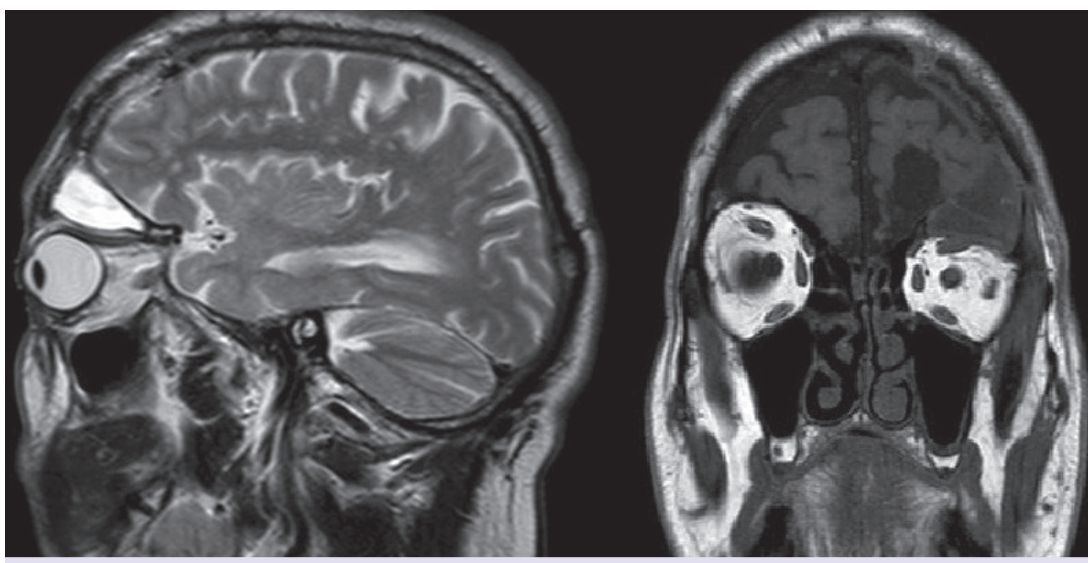

FIGURE 4. Postoperative MRI revealed that mucopyocele had been excised. 
providing information about coronal, sagittal, axial planes and enabling three dimensional studies [8, 9]. In our case, mucopyocele was diagnosed using MRI. A CT scan was performed to demonstrate the relationship between mucopyocele and the adjacent bones and bony destruction which canalized our plan of surgical procedure.

The treatment of mucocele is surgical [5]. Although various surgical methods have been defined and performed, there is no consensus about surgical treatment modalities $[7,10]$. Traditionally, treatment for paranasal sinus mucocele involved complete resection of the mucosal lining, and obliteration of the sinus. Obliteration of the involved sinus is not recommended if there is erosion of the sinus bony wall with extension of the mucocele either intracranially or into the orbit. Mucoceles are treated surgically either with external approach or endoscopic approach $[9,10]$. During long-term follow-up of patients who underwent endoscopic marsupialization, recurrences have been rarely (if any) encountered $[7,10]$. Obeso et al. performed endoscopic marsupialization in 48 of 72 cases of mucocele and external approach in the remaining cases and reported lower recurrence rates for the endoscopic approach [9]. However, external approach is recommended in the complicated, and infected mucoceles which destructed the bones severely $[5,10]$. Khong et al. treated 15 of 24 cases of mucocele via an endoscopic approach and reported a recurrence rate of 27 percent [10]. Since in our case mucocele was infected and extended into the orbital cavity with destruction of the orbital roof, external approach was preferred.

Since normal histological structure is preserved in most of the cases, excision of the mucocele wall is controversial. It is suggested that the mucocele wall is an ideal lining for the developing cavity, and its removal is not appropriate [9]. However, this suggestion is not valid for the cases of mucopyocele complicated with infection and extending into the surrounding tissues secondary to bony destruction. In these cases, since it reduces the risk of recurrence, removal of mucocele or mucopyocele with its capsule and cranialization of the sinus are recommended $[1,5]$. In our case, the mucopyocele was removed with its capsule and frontal sinus cranialization was performed.

In conclusion, removal of mucopyocele with its capsule and cranialization of the sinus is an appropriate treatment choice for the cases of mucocele complicated by infection and extending from frontal sinus into the orbital cavity with resultant widespread bony destruction.

Conflict of Interest: No conflict of interest was declared by the authors.

Financial Disclosure: The authors declared that this study has received no financial support.

\section{REFERENCES}

1. Chiarini L, Nocini PF, Bedogni A, Consolo U, Giannetti L, Merli GA. Intracranial spread of a giant frontal mucocele: case report. Br J Oral Maxillofac Surg 2000;38:637-40. CrossRef

2. Palmer-Hall AM, Anderson SF. Paraocular sinus mucoceles. J Am Optom Assoc 1997;68:725-33.

3. Maliszewski M, Ladziński P, Kaspera W, Majchrzak K. Mucocoele and mucopyocoele of the frontal sinus penetrating to the cranial cavity and the orbit. Neurol Neurochir Pol 2011;45:342-50.

4. Delfini R, Missori P, Iannetti G, Ciappetta P, Cantore G. Mucoceles of the paranasal sinuses with intracranial and intraorbital extension: report of 28 cases. Neurosurgery 1993;32:901-6. CrossRef

5. Gall R, Witterick I. Mucocele of the nasal septum. J Otolaryngol 2002;31:246-7. CrossRef

6. Har-El G. Endoscopic management of 108 sinus mucoceles. Laryngoscope 2001;111:2131-4. CrossRef

7. Sautter NB, Citardi MJ, Perry J, Batra PS. Paranasal sinus mucoceles with skull-base and/or orbital erosion: is the endoscopic approach sufficient? Otolaryngol Head Neck Surg 2008;139:570-4.

8. Kennedy DW, Josephson JS, Zinreich SJ, Mattox DE, Goldsmith MM. Endoscopic sinus surgery for mucoceles: a viable alternative. Laryngoscope 1989;99:885-95. CrossRef

9. Obeso S, Llorente JL, Pablo Rodrigo J, Sánchez R, Mancebo G, Suárez C. Paranasal sinuses mucoceles. Our experience in 72 patients. [Article in Spanish] Acta Otorrinolaringol Esp 2009;60:332-9. [Abstract] CrossRef

10. Khong JJ, Malhotra R, Wormald PJ, Selva D. Endoscopic sinus surgery for paranasal sinus mucocoele with orbital involvement. Eye (Lond) 2004;18:877-81. CrossRef 